\title{
Dissection notes: first day
}

Cite as: CMAJ 2020 May 4;192:E486. doi: 10.1503/cmaj.191552

Wrapped in black plastic, a gift to science waits in the cold laboratory. Your pupils, moon-round and flat, reflect my face when I unzip your body. Thick, damp hair flows across twin scars on your chest, suggesting cancer. From the clefts below your hips, two tattooed roses bloom in the silence between us. As fear and sacredness touch, my scalpel hovers over your skin. The living resort to action when words don't offer anything much by way of introduction.

\section{Doug Hester MD MFA}

Anesthesiology, Vanderbilt University Medical Center, Nashville, Tenn.

This article has been peer reviewed.

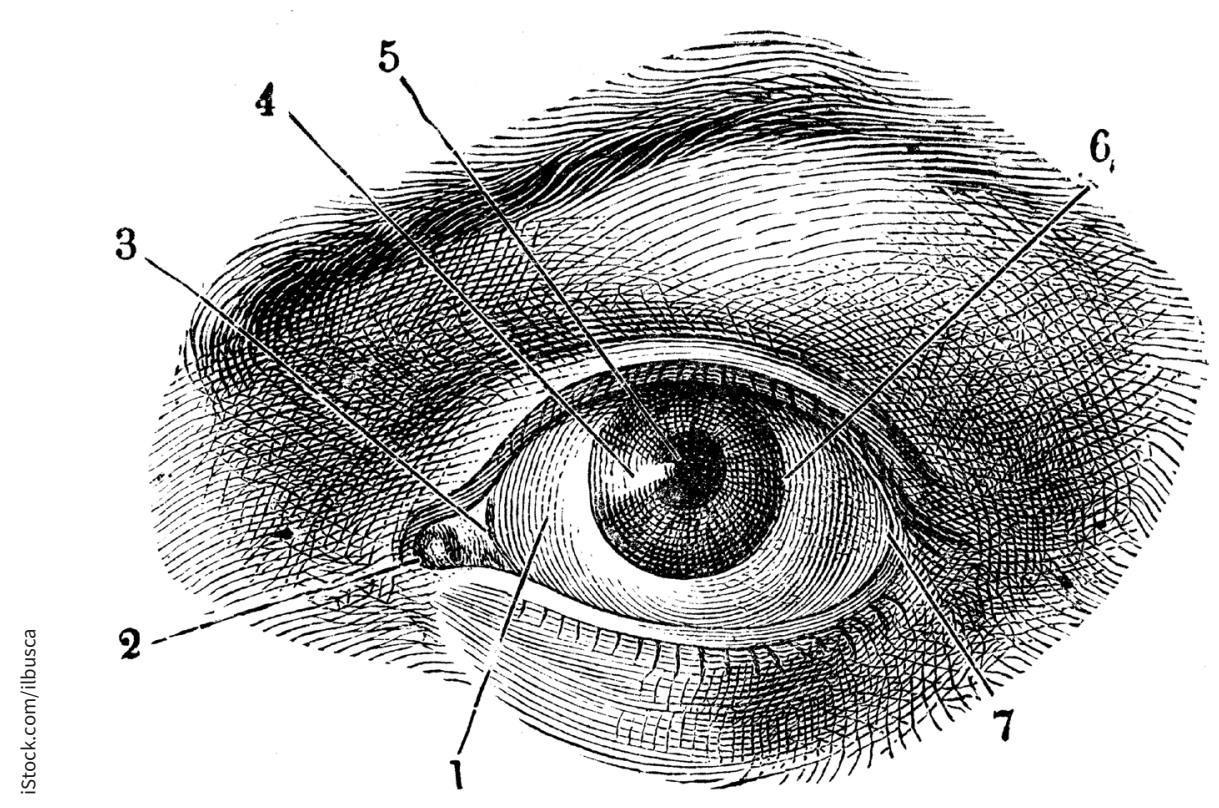

